\title{
Enhanced Reactivity and Vulnerability to Cocaine Following Methylphenidate Treatment in Adolescent Rats
}

\author{
Cindy L. Brandon, M.A., Michela Marinelli, Ph.D., Lorinda K. Baker, B.A., and Francis J. White, Ph.D.
}

Treatment of attention deficit hyperactivity disorder with the psychostimulant drug methylphenidate (MP) has increased dramatically among schoolchildren. We tested whether repeated exposure to moderate doses of MP (5 and $10 \mathrm{mg} / \mathrm{kg}$ IP for 5 or 7 days) in adolescent rats increased reactivity to cocaine measured by motor responses (ambulations and rearing) to a cocaine challenge in adulthood. We later tested whether repeated exposure to a low dose of MP (2 mg/kg IP for 7 days) enhanced the psychomotor effects of cocaine, measured by different challenge doses $(0-30 \mathrm{mg} / \mathrm{kg})$ as well as to the reinforcing effects of cocaine, measured by self-administration of lowdose infusion $(75 \mu \mathrm{g} / \mathrm{kg}, I V)$. We found that exposure to moderate doses of MP enhanced psychomotor responses to cocaine but exposure to a low dose only increased cocaine self-administration. These results suggest that adolescent exposure to low doses of MP in rats may increase the incentive value of low reinforcers, thereby rendering adult rats more susceptible to cocaine self-administration.

[Neuropsychopharmacology 25:651-661, 2001] (C) 2001 American College of Neuropsychopharmacology. Published by Elsevier Science Inc.
KEY WORDS: Attention deficit hyperactivity disorder; Selfadministration; Sensitization; Ritalin $^{\circledR}$; Substance abuse disorder; Addiction

Methylphenidate $\left(\operatorname{Ritalin}^{\circledR}\right)$ is used widely in the treatment of attention deficit hyperactivity disorder (ADHD), the most commonly diagnosed disorder of childhood (Swanson et al. 1998). During the 1990s, diagnosis and treatment of this disorder grew dramatically in the United States. Estimates show that up to $15 \%$ of school

From the Departments of Cell Biology and Anatomy (CLB) and Cellular and Molecular Pharmacology, (MM, LKB, FJW) Finch University of Health Sciences/The Chicago Medical School, North Chicago, Illinois, USA.

Address correspondence to: Francis J. White, Ph.D., Professor and Chair, Department of Cellular and Molecular Pharmacology, Finch University of Health Sciences/The Chicago Medical School, 3333 Green Bay Rd.,North Chicago, IL 60064. Tel.: 847-578-3270; Fax: 847-578-3268, e-mail:whitef@finchcms.edu

Received January 2, 2001; revised April 20, 2001; accepted April 20, 2001.

Online publication: 4/25/01 at www.acnp.org/citations/Npp 042501111. age children may be affected in certain geographical locations (Scahill and Schwab-Stone 2000) and that prevalence is estimated to be $5-10 \%$ in the general population (Swanson et al. 1998). In addition, preschoolers (Zito et al. 2000) and children who do not meet the diagnostic criteria for ADHD (Marshall 2000) have recently been identified as two new groups increasingly exposed to this drug. The duration of treatment is several years in childhood, more often extending into adolescence and adulthood (Garland 1998; Robin 1999; Silver 2000; Spencer et al. 2000).

Animal studies have shown that MP is a psychostimulant, which, as with cocaine, blocks the dopamine transporter (DAT) (Kuczenski and Segal 1997); thereby increasing extracellular dopamine (DA) levels in the striatum and nucleus accumbens (Kuczenski 1983), brain regions involved in the locomotor and reinforcing effects of psychostimulants and other drugs of abuse (Koob and Bloom 1988). Recent human brain imaging studies indicate that MP and cocaine have similar in vivo potency to block the DAT in human brain (Volkow 
et al. 1999). Oral therapeutic doses of MP effectively block more than $50 \%$ of DATs (Volkow et al. 1998); thereby increasing extracellular DA levels (Volkow et al. 2001). These actions are highly associated with the reinforcing properties of drugs (Ritz et al. 1987). Taken together, the well-documented abuse potential of psychostimulants (for reviews see White and Wolf 1991; Robinson and Berridge 1993; Self and Nestler 1995), studies linking ADHD with subsequent substance abuse (Wilens et al. 1997; Clure et al. 1999; Schubiner et al. 2000), and the dearth of controlled studies on the effects of long-term stimulant exposure on the brain, all make MP exposure an important public health issue.

Animal models of drug addiction clearly indicate that repeated exposure to psychostimulants results in augmented behaviors (sensitization) that can be detected long after final drug exposure (see Robinson and Becker 1986 for review). Locomotor sensitization results from a variety of neuroadaptations (see White and Kalivas 1998 for review) associated with processes underlying addiction (see Robinson and Berridge 1993 for review). Accordingly, critical questions about treatment of ADHD with psychostimulants are: do children and adolescents sensitize during repeated drug exposure and, if so, does sensitization persist? Unfortunately, animal studies have provided conflicting answers (Laviola et al. 1995; Ujike et al. 1995; Snyder et al. 1998; Wood et al. 1998; Izenwasser et al. 1999; McDougall et al. 1999; Zavala et al. 2000). Sensitization to MP in rodent models has been well documented (Shuster et al. 1982; Gaytan et al. 1997; Crawford et al. 1998; but see McNamara et al. 1993), but the use of relatively high doses in most studies, and the apparent inability of MP to induce long-term locomotor sensitization in young animals (McDougall et al. 1999), has raised questions regarding the clinical relevance of such findings (National Institute of Mental Health 1999).

Animal studies have also shown that repeated exposure to psychostimulants increases the likelihood that rats will acquire drug self-administration (SA) with shorter latencies (Horger et al. 1992) and at lower doses (Horger et al. 1990), perhaps a more relevant display of sensitization as it relates to addiction. Pretreatment with such stimulants as nicotine, caffeine, and amphetamine produces enduring enhancements in the acquisition of cocaine SA (Valdez and Schenk 1994; Schenk and Davidson 1998). Clearly, history of drug exposure influences subsequent vulnerability to substance abuse. However, there are no reports of whether adolescent MP exposure in animals enhances vulnerability to drug SA. In humans, conflicting reports propose that therapeutic exposure to MP is either a risk factor for later substance abuse (e.g., see Lambert in press), is unrelated to subsequent substance abuse (e.g., Biederman et al. 1995) or actually protects individuals from subsequent substance use disorders (e.g., see Biederman et al. 1999). The difficulties involved in conducting controlled studies in human ADHD populations undoubtedly contribute to the uncertain and controversial nature of the current literature.

A related question regarding the therapeutic use of MP focuses on route of administration as it relates to both pharmacokinetics and drug-induced euphoria. Certain reports suggest that MP is rarely abused except when taken intravenously (e.g., see Parran and Jasinski 1991). The oral route of administration may blunt MP's reinforcing effects because of pharmacokinetics in brain and plasma (Gerasimov et al. 2000), and slow kinetics of DAT blockade (Volkow et al. 1998). A recent microdialysis study addressed differences between oral (intragastric) and IP routes of MP administration, using extracellular DA levels within the nucleus accumbens as a neurochemical measure. The authors concluded that matching peak MP plasma concentrations in humans and rats might not be appropriate for choosing clinically relevant doses, because much higher doses are required in animals to sustain what would be appropriate therapeutic levels in humans, and such doses induce higher peak plasma levels than are therapeutically relevant (Gerasimov et al. 2000). These results suggest that MP doses of less than $5 \mathrm{mg} / \mathrm{kg}$ IP in rats might be comparable to those used clinically for the following reasons: (1) they produce sustained plasma levels without overshooting the peak; (2) lower doses administered intragastrically to rodents do not raise DA levels above baseline; whereas, doses as low as $0.5-1.0 \mathrm{mg} / \mathrm{kg}$ administered orally to humans significantly increase DA levels in the striatum (Volkow et al. 2001); and (3) a $5 \mathrm{mg} / \mathrm{kg}$ intragastric dose is approximately equivalent to the $2.0 \mathrm{mg} / \mathrm{kg}$ IP dose for both the enhanced DA and locomotor responses in rodents.

We designed the present study to address several unanswered questions regarding adolescent psychostimulant exposure in rats. We sought to: (1) assess whether adolescent rats develop persistent behavioral sensitization to cocaine; (2) determine whether repeated exposure to moderate doses of MP during adolescence enhances the locomotor stimulant effects of cocaine in adulthood; and (3) determine whether repeated exposure to low doses of MP (which may be more therapeutically relevant in terms of pharmacokinetics and bioavailability as well as behavioral and neurochemical effects) in adolescent rats produces locomotor sensitization to cocaine and increases vulnerability to cocaine SA in adulthood. The advantage of conducting such studies in rats is the ability to control independent variables carefully and to avoid confounds that render clinical studies subject to multiple interpretations. The major caveat is the extent to which dose and pharmacokinetic variables in rats accurately model MP treatment of ADHD in humans. 


\section{MATERIALS AND METHODS}

\section{Repeated Drug Treatment}

Four-week-old male Sprague-Dawley rats (Harlan, Indianapolis, IN) were individually housed and allowed 1 week for acclimation to the vivarium (12:12 light/ dark; lights on 7:00 AM) where there was constant humidity $(66 \%)$, temperature $\left(21-23^{\circ} \mathrm{C}\right)$, and ad libitum food and water. Animals were then injected IP in their home cages with either a saline vehicle $(0.9 \% \mathrm{NaCl})$, cocaine $(15 \mathrm{mg} / \mathrm{kg})$, or MP $(2,5$, or $10 \mathrm{mg} / \mathrm{kg}$ dissolved in saline) for 5 or 7 days (3-5 h before lights off, once per day). They were then allowed 2 weeks before further behavioral testing (locomotor test or SA test), during which they were handled and weighed twice.

\section{Locomotor Test}

In a separate behavioral testing facility, 12 photobeam activity detection devices (PAS monitoring system, San Diego Instruments, San Diego, CA) were mounted around standard rectangular transparent rodent cages $(30 \times 50 \times 25 \mathrm{~cm})$. A lower frame was equipped with three photoelectric beams, which divided the long axis of the cage into four quadrants $(12.5 \times 30 \mathrm{~cm}$ each). In addition, upper rearing beams (8 photocells) were located along the $30-\mathrm{cm}$ side of the cage. Interruptions of photobeams generated digital pulses, which were computer analyzed to determine both the total number of photobeam interruptions and the interruptions of consecutive photobeams (ambulations, lower beams only). Animals were allowed $1 \mathrm{~h}$ habituation before a cocaine challenge. Locomotor activity was measured for $1 \mathrm{~h}$ divided into 5-min intervals. Dose- response analyses of cocaine responses following low-dose MP exposure were conducted on four separate days, with cocaine dose assigned randomly in separate groups of rats for each dose.

\section{Surgery and Cocaine Self-Administration}

Rats to be used in SA experiments were surgically implanted with jugular catheters 1 week following the last drug treatment, which consisted of seven daily injections of MP $(2.0 \mathrm{mg} / \mathrm{kg} \mathrm{IP})$ or saline. Each rat was anesthetized with a ketamine/xylazine solution $(65 \mathrm{mg} / \mathrm{kg}$ and $20 \mathrm{mg} / \mathrm{kg}$, respectively, in a $1-\mathrm{ml} / \mathrm{kg}$ volume) and implanted with a silastic catheter (10 $\mu \mathrm{l}$ dead volume) fashioned to secure it into the right auricle through the external jugular vein. The catheter was passed subcutaneously exiting in the midscapular region. After surgery and on the two subsequent days, all rats received an infusion of the antibiotic gentamycin $(2 \mathrm{mg} / \mathrm{kg}$ IV). Thereafter, the catheter was flushed daily with a solution of heparin $(100 \mu \mathrm{l}$ containing $10 \mathrm{IU})$. Saline $(50 \mu \mathrm{l})$ was flushed at the start of each SA session, every day, and heparin was flushed at the end of the session. Animals entered the SA boxes fitted with a tether, and the external end of the catheter was connected to a pumpdriven syringe. The infusion line was passed through a swivel joint. The SA cages (MED Associates, St. Albans, VT) had an extra-wide Malagard sound cubicle with an interior operant chamber $(41 \times 24 \mathrm{~cm}$ floor area, $21 \mathrm{~cm}$ high). Nose-poke holes were located $2 \mathrm{~cm}$ above the floor in one of the $24 \mathrm{~cm}$-wide sides of the cage.

Nose poking in one of the holes (defined as "active") switched on the infusion pump for $3 \mathrm{~s}$, injecting $30 \mu \mathrm{l}$ of a $75 \mu \mathrm{g} / \mathrm{kg}$ dose of cocaine. Each reinforcer was accompanied by a 5-s light in the nose-poke hole and a 5- s time out, during which hole poking had no consequence. A fixed ratio 1 schedule of reinforcement was used throughout the experiment. No priming injections were given at any time. Poking at the inactive hole had no programmed consequence. The number of nosepokes in both holes and the number of infusions were recorded throughout the experiments. Each rat received one session per day ( $3-5 \mathrm{~h}$ before lights out) for $1 \mathrm{~h}$ for 5 days. The MED Associates Software Package Schedule Manager for Windows controlled drug delivery and data collection, including monitoring of locomotor activity. The behavior program was custom designed by MED Associates (MED Test for Windows). Rats were considered to perform active SA when the number of nose-pokes in the active hole was significantly higher than the number in the inactive hole $(95 \%$ confidence limit). Catheter patency was confirmed the last day of the experiment by delivering sodium pentobarbital solution $(10 \%)$ through the catheter. Rats that did not succumb within $5 \mathrm{~s}$ were eliminated from the study.

Locomotor activity during self-administration was monitored by two photobeams on the long wall of the operant chamber measuring total counts. Accordingly, noticeably higher activity counts were generated than in the locomotor activity boxes described above. All experiments were performed in accordance with the Guide for the Care and Use of Laboratory Animals (NIH Publication No. 85-23).

\section{Drugs}

Methylphenidate $\mathrm{HCl}$ and cocaine $\mathrm{HCl}$ were generously provided by the National Institute on Drug Abuse (Rockville, MD). Gentamycin was purchased from ICN Biomedical Inc. (Costa Mesa, CA). Xylazine was obtained from Phoenix Scientific Inc. (St. Joseph, $\mathrm{MO})$. Ketamine and heparin were purchased from Sigma Chemical Co. (St. Louis, MO).

\section{Statistical Analyses}

Locomotor tests were analyzed with Student's $t$-tests for the three separate time points for cocaine sensitiza- 
tion following repeated cocaine. Student's $t$-tests were also used for the dose-response tests to cocaine following low-dose exposure to MP. Psychomotor responses for cross sensitization between MP (at moderate doses) and cocaine were analyzed using repeated measures analysis of variance (ANOVA). This analysis considered the treatment (saline vs. MP) as the between factor and time (12 levels) as the within factor. SA experiments were analyzed with repeated measure ANOVAs. This analysis considered the treatment (saline vs. MP) as between factors and the following as within factors when necessary: Hole effect (two levels: Active hole vs. Inactive hole), Days effect (five levels: days 1-5).

\section{RESULTS}

\section{Adolescent Rats Show Persistent Locomotor Sensitization Following Repeated Cocaine}

As shown in Figure 1, 5-week-old rats that received repeated cocaine injections ( $15 \mathrm{mg} / \mathrm{kg}$ IP for 5 days) exhibited an enhanced locomotor response relative to saline-pretreated rats, when challenged with cocaine at half the sensitizing dose $(7.5 \mathrm{mg} / \mathrm{kg} / \mathrm{IP})$. This was observed in three separate experiments using separate groups of rats at withdrawal days 3,14 , and 60 with the sensitized response being greater at the longer withdrawal times.

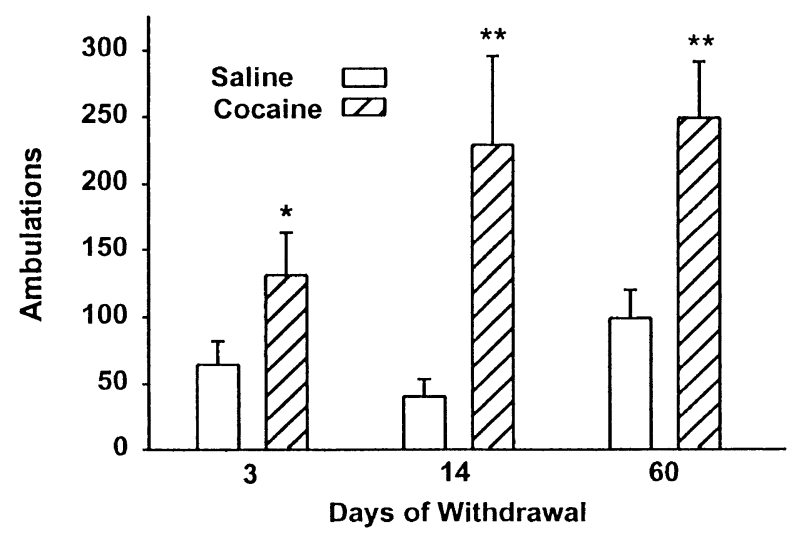

Figure 1. Repeated exposure to cocaine during adolescence causes long-term sensitization. Three individual experiments using the same protocol for sensitization to cocaine $(15 \mathrm{mg} /$ $\mathrm{kg}$ IP daily for 5 days in the home cage) show that at withdrawal day $3\left(t_{22}=-1.81, p=.041\right), 14\left(t_{22}=-2.77, p=.005\right)$, and $60\left(t_{22}=-3.17, p=.002\right)$ locomotor responses are significantly greater in the cocaine pretreated groups $(n=12)$ compared to those pretreated with saline $(n=12)$. Bars represent means \pm SEM.

\section{Repeated Exposure to Methylphenidate in Adolescent Rats Results in Enhanced Reactivity to Cocaine in Adulthood}

Moderate Dose Exposure to MP. Following 7 days of repeated IP injections of a moderate dose of MP (10 $\mathrm{mg} / \mathrm{kg}$ /day), 5-week-old rats were allowed 2 weeks of withdrawal in their home cages. At 8 weeks of age, these (now adult) rats were challenged with a threshold dose $(7.5 \mathrm{mg} / \mathrm{kg} \mathrm{IP})$ of cocaine. Our results (Figure 2) clearly indicate that pre-exposure to MP significantly
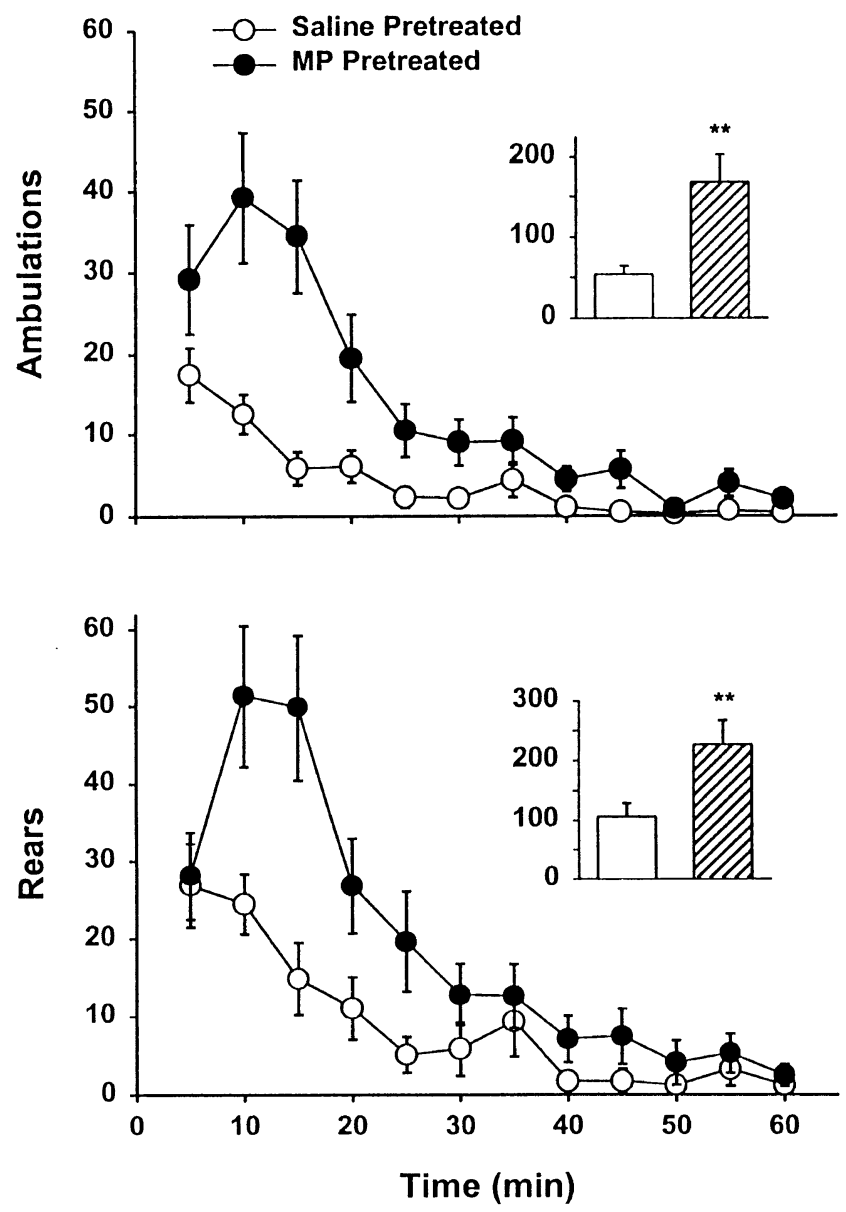

Figure 2. Adolescent rats pretreated with $\mathrm{MP}(10 \mathrm{mg} / \mathrm{kg})$ show enhanced reactivity to cocaine in adulthood. The psychomotor response to a cocaine challenge $(7.5 \mathrm{mg} / \mathrm{kg})$ measured in (upper panel) ambulations and (lower panel) rears, was significantly enhanced in MP-pretreated rats $(n=12)$ (10 mg/kg IP daily for 7 days, in the home cage) as compared to saline pretreated rats $(n=12), 2$ weeks following their last exposure and simultaneous development into adult rats (main effect treatment: $\mathrm{F}_{1,22}=10.28, p=.004$; treatment $\times$ time interaction: $\mathrm{F}_{11,242}=6.22, p<.0001$, ambulations as dependent variable; main effect treatment: $\mathrm{F}_{1,22}=$ $6.70, p=.017$; treatment $\times$ time interaction: $\mathrm{F}_{11,242}=4.48, p<$ .0001 , rears as dependent variable). Inset bar graphs show total counts over the $1-\mathrm{h}$ test session. Datapoints and bars represent mean \pm SEM. 
increased sensitivity to the locomotor activating effects of cocaine (both horizontal and vertical).

In a separate experiment, following the same proto$\mathrm{col}$, we used a lower dose of MP (5 mg/ $\mathrm{kg} /$ day IP) in the pre-exposure phase and a larger challenge dose of cocaine $(15 \mathrm{mg} / \mathrm{kg} \mathrm{IP})$ on the challenge day. Again, Figure 3 clearly shows that there is significant cross sensitization to the cocaine challenge measured in both ambulations and rearing. Although it is possible that the MP-treated rats were more responsive to a novel testing environment rather than more responsive to the cocaine challenge, this is unlikely, because our rats
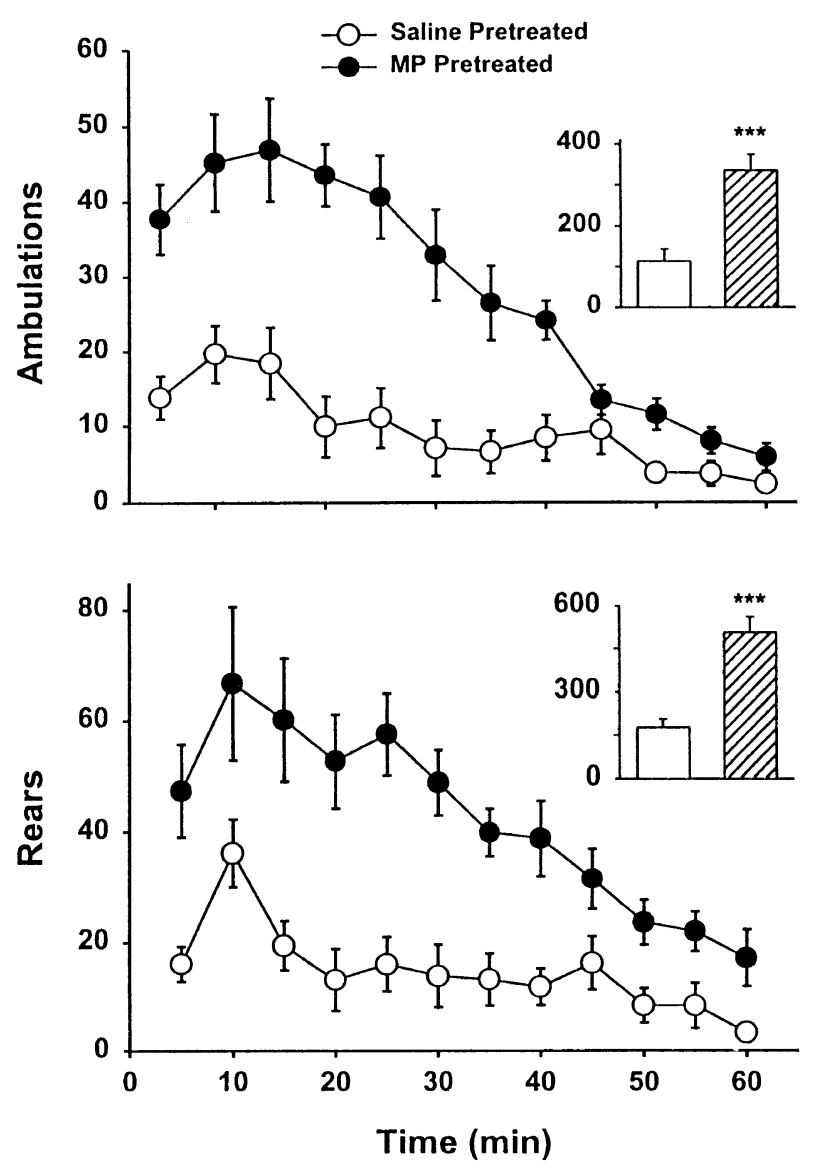

Figure 3. Adolescent rats pretreated with $\mathrm{MP}(5 \mathrm{mg} / \mathrm{kg})$ show enhanced reactivity to cocaine in adulthood. The psychomotor response to a cocaine challenge $(15 \mathrm{mg} / \mathrm{kg})$ measured in (upper panel) ambulations and (lower panel) rears, was significantly enhanced in MP-pretreated rats $(n=12)$ ( $5 \mathrm{mg} / \mathrm{kg}$ IP daily for 5 days in the home cage) compared to saline pretreated rats $(n=12), 2$ weeks following their last exposure and simultaneous development into adult rats (Main effect treatment: $F_{1,22}=21.16, p<.0001$, Treatment $\times$ time interaction $F_{11,242}=8.02, p<.001$, ambulations as dependent variable; Main effect treatment $F_{1,21}=29.05, p<$ .001 , Treatment $\times$ time interaction, $F_{11,231}=2.16, p=.018$, rears as dependent variable). Inset bar graphs show total counts over the 1-h test session. Datapoints and bars represent mean \pm SEM. were habituated to the test environment for $1 \mathrm{~h}$ before the cocaine injection. Even if this were the case, it would also suggest that the MP-pretreated rats were sensitized, given the well-known association between drug sensitivity and responses to a novel environment (Piazza and Le Moal 1996). Therefore, moderate doses of MP administered during adolescence affect over-all reactivity to cocaine following development into adulthood and withdrawal from drug exposure.

\section{Low-Dose Exposure to MP}

Locomotor Response to Cocaine (Dose-Response Test). To emulate more closely the dosing regimens and plasma drug concentrations that occur most frequently in humans (Gerasimov et al. 2000), we pretreated adolescent rats with a low dose of MP $(2 \mathrm{mg} / \mathrm{kg} /$ day IP) for 7 days. Following repeated treatment, we challenged separate groups of rats with different doses of cocaine $(0,3.75,7.5,15$, and $30 \mathrm{mg} / \mathrm{kg}$ IP on separate days with cocaine dose assigned randomly). Figure 4 clearly shows that at this low dose of MP, repeated exposure does not enhance the locomotor or rearing response to cocaine at any dose tested.

Cocaine Self-Administration. Using the low-dose MP treatment protocol, we determined whether adult rats would acquire SA of cocaine at a low dose of $75 \mu \mathrm{g} /$ $\mathrm{kg} /$ infusion. SA training commenced 2 weeks following the last MP injection and 1 week following surgery for implantation of IV catheters. MP pretreatment clearly enhanced SA of cocaine, as compared to saline pretreatment. MP pretreatment enhanced intake of cocaine measured by significantly more self-infusions (Figure 5) and more nose pokes at the active hole (Figure 6). There were no significant differences between the two groups of rats with respect to responding in the inactive hole. In addition, there was no statistical difference between the saline and MP-pretreated group for poking at the inactive hole on day 1 of SA, further indicating that greater nose-poking at the active hole was not the result of nonselective activity in the MP group. Both the saline and MP-pretreated groups showed acquisition of cocaine SA measured by their ability to discriminate between the active and inactive hole (Figure 6). In addition, we measured locomotor activity during cocaine SA (Figure 5). The MP-pretreated group showed enhanced motor activity during cocaine SA, as compared to the saline pretreated group, which was expected, given that they injected considerably more cocaine.

\section{DISCUSSION}

We found that adolescent exposure to cocaine caused a robust and persistent sensitization to its psychomotor 

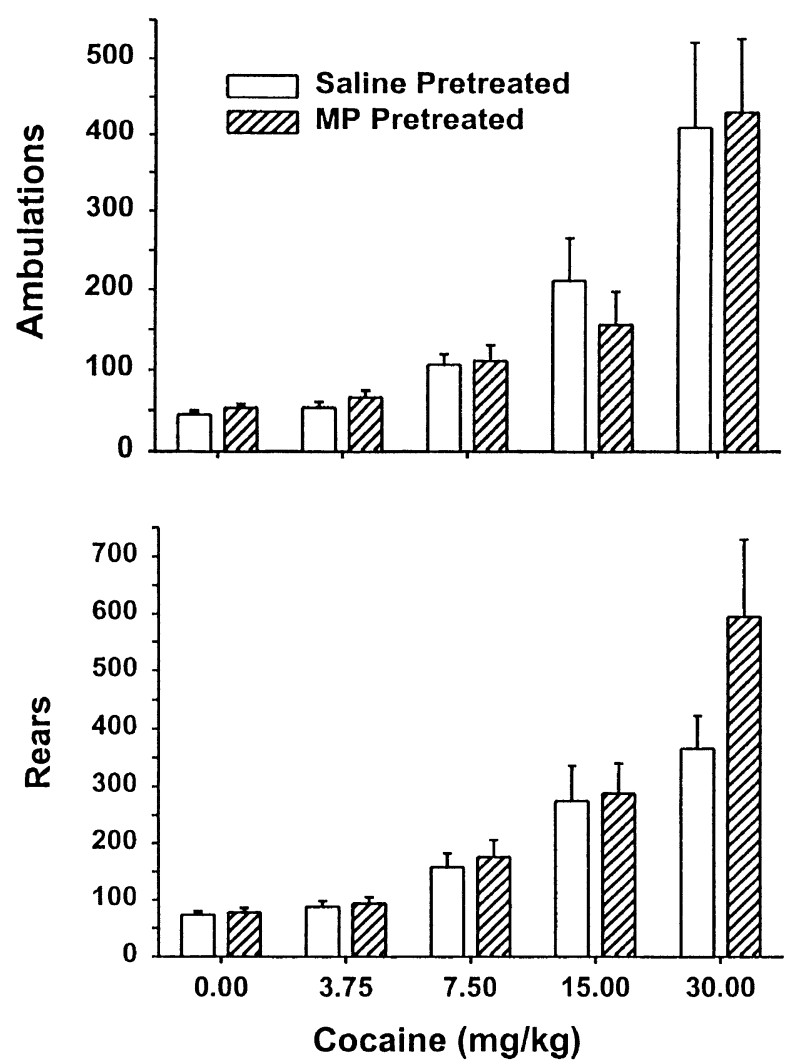

Figure 4. Adolescent exposure to a low dose of methylphenidate does not enhance reactivity to cocaine: psychomotor response. The psychomotor response to five challenge doses of cocaine $(0,3.75,7.5,15$, and $30 \mathrm{mg} / \mathrm{kg}$ tested in separate groups of rats) measured in (upper panel) ambulations, and (lower panel) rears, is not enhanced following low dose ( $2 \mathrm{mg} / \mathrm{kg}$ IP daily for 7 days in the home cage) exposure to MP in adolescent rats. Bars represent mean \pm SEM $(n=$ 8-20/group). Statistics are as follows: Dose 0 Ambulations: $t_{26}=-1.30, p=.20$, Rears $\left(t_{26}=-.468, p=.64\right)$; Dose 3.75 Ambulations $\left(t_{30}=-1.29, p=.207\right)$, Rears $\left(t_{30}=-.370, p=\right.$ $.71)$; Dose $7.5 \mathrm{mg} / \mathrm{kg}$ Ambulations $\left(t_{38}=-0.196, p=.846\right)$, Rears $\left(t_{38}=-.476, p=.64\right)$; Dose $15 \mathrm{mg} / \mathrm{kg}$ Ambulations $\left(t_{14}=\right.$ $.806, p=.43)$, Rears $\left(t_{14}=-.158, p=.87\right) ;$ Dose $30 \mathrm{mg} / \mathrm{kg}\left(t_{14}=\right.$ $-1.37 p=.892)$, Rears $\left(t_{14}=-1.568, p=.139\right)$.

stimulant effects following 3 days, 2 weeks, and 2 months of cocaine withdrawal. In addition, we also observed cross sensitization from MP to cocaine. Such cross sensitization occurred with two moderate MP pretreatment doses and with two different cocaine challenge doses. When we switched to a lower dose of MP, one that results in plasma MP levels closer to those achieved clinically (Gerasimov et al. 2000), we no longer observed cross sensitization to the locomotor stimulant effects of cocaine. However, such MP-pretreated rats showed greater SA of a low dose of cocaine. Thus, adult animals exposed to MP during adolescence were considerably more vulnerable to the reinforcing effects of cocaine. Our results clearly demonstrate dis-
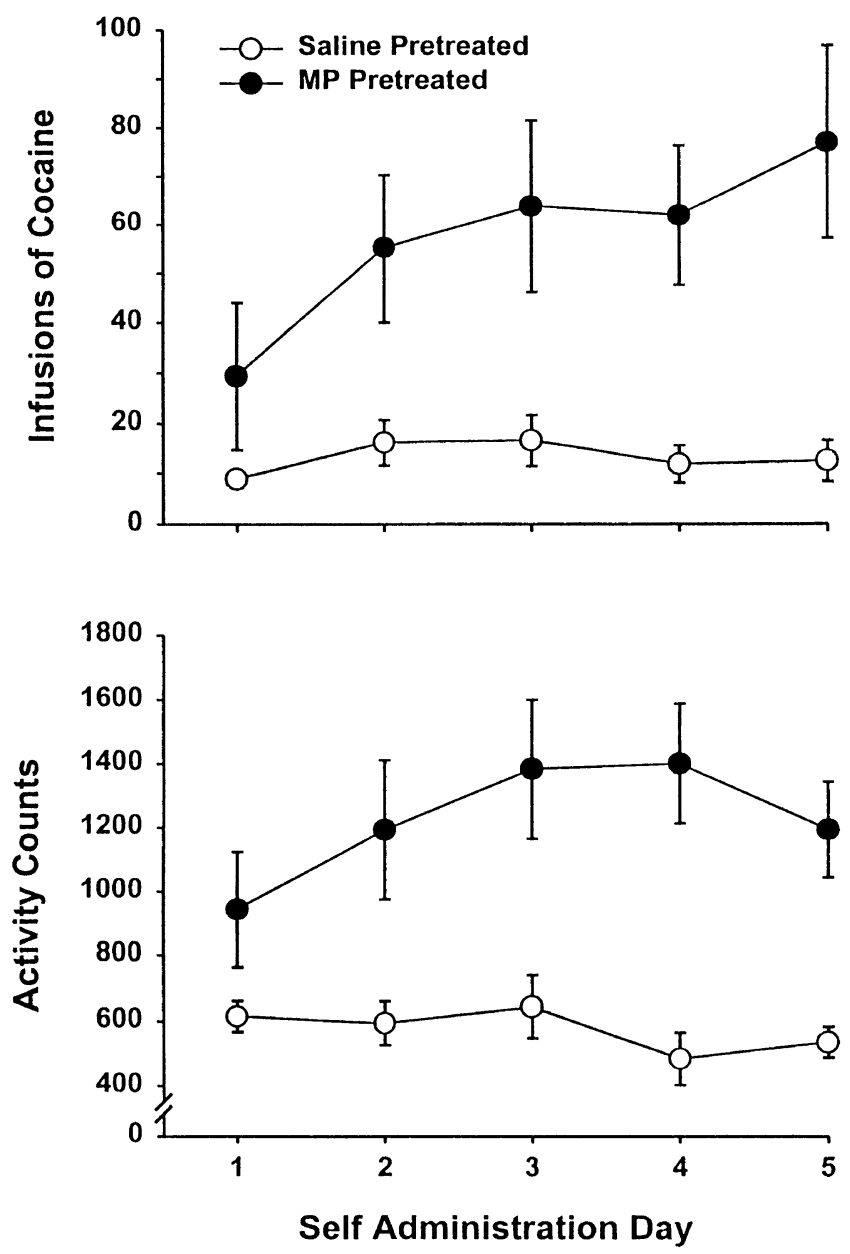

Figure 5. Adolescent rats pretreated with MP show increased vulnerability to cocaine self-administration. Upper panel: Increased intake during self-administration of a low dose of cocaine (75 $\mu \mathrm{g} / \mathrm{kg} /$ infusion), 2 weeks following lowdose exposure to MP ( $2 \mathrm{mg} / \mathrm{kg}$ IP daily for 7 days in the home cage) during adolescence. Cocaine self-administration was significantly greater in MP-pretreated rats $(n=12)$ compared to saline pretreated rats $(n=10)$. Main treatment effect: $F_{1,20}=$ $8.90, p=.007$ with infusions as the dependent variable. Lower panel: Daily locomotor response to self-administration of cocaine. Main treatment effect: $F_{1,20}=12.15, p=.002$ with photobeam breaks as the dependent variable.

sociation between the psychomotor stimulant effects of cocaine and its ability to support SA following adolescent exposure to MP.

\section{Ontogeny of Behavioral Sensitization}

Ontogenetic studies indicate that after cocaine treatment during pre-weanling (Zavala et al. 2000; Snyder et al. 1998; Wood et al. 1998), post- weanling (Ujike et al. 1995) and peri-adolescent periods (Laviola et al. 1995), rats develop an enhanced behavioral response to cocaine. Unlike previous studies (Laviola et al. 1995), we 


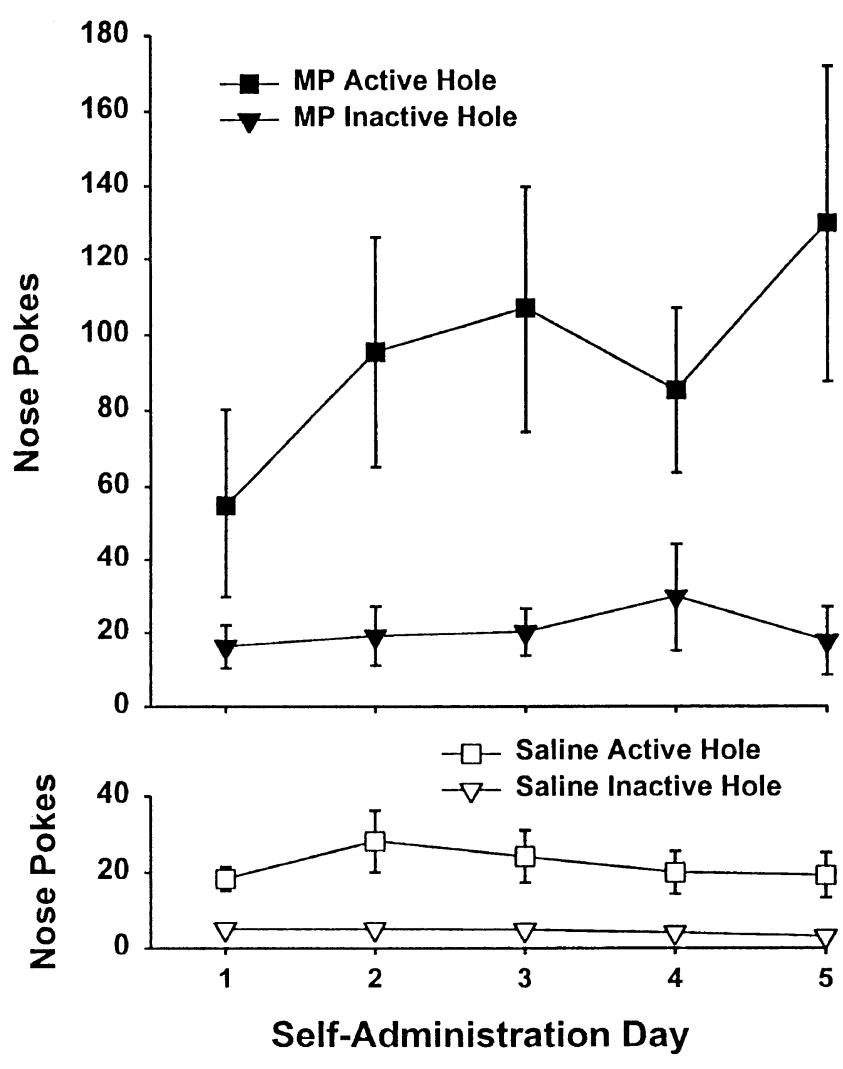

Figure 6. Acquisition of cocaine self-administration: active versus inactive hole. Following adolescent exposure to saline (lower panel) or MP (upper panel) both groups of animals learned cocaine self-administration measured by discrimination of the active versus inactive hole: saline group $F_{1,9}=13.71, p=.005$; MP group $\left.F_{1,11}=15.11, p=.002\right)$. In addition, the MP group showed greater responding at the active hole compared to the saline group (treatment effect, $F_{1,20}=7.59, p=.012$ ) but not significantly greater responding at the inactive hole (treatment effect, $F_{1,20}=3.41, p=$ .079). Moreover, there was no significant difference between the two groups with respect to inactive hole poking on the first SA session $\left(t_{20}=-1.760, p>.05\right)$, indicating that the higher rates of cocaine SA were not attributable to hyperactivity in the MP-pretreated group.

observed increasing sensitization to the locomotor stimulant effects of cocaine over time. This response was not dependent on environmental context, because animals were only exposed to the behavioral testing facility once on the test day; whereas, repeated cocaine exposure occurred in home cages. Sensitization seems to occur only when the sensitizing regimen is restricted to late pre-weanling life or later and when repeated drug exposure is paired with the testing chamber or when long pretreatment regimens are used. Sensitization may be limited to short treatment-to-test intervals (McDougall et al. 1994; Tirelli and Ferrara 1997; Wood et al. 1998) although other studies indicate persistent sensitization (Snyder et al. 1998; Zavala et al. 2000).
We found that in 4 to 5 -week-old rats, which are ageequivalent to the beginning of peri-adolescence, pairing of stimulant exposure with the testing environment was not necessary to obtain sensitization. Rats received repeated treatment of cocaine in their home cages and exhibited locomotor sensitization to a challenge dose of cocaine $(7.5 \mathrm{mg} / \mathrm{kg})$ that was half the repeated treatment dose following a 1-h habituation in the context of a novel testing facility. This response lasted 3-60 days following the last treatment, which is longer than any previous study has reported for rats of this age, and suggests that neuroadaptations occurring at this time might be more persistent than in older animals (e.g., see Henry and White 1995) or younger animals (above).

The progression of psychostimulant use and abuse seems to be more rapid among human adolescents than among adult abusers (Estroff et al. 1989; Laviola et al. 1999). This suggests that exposure to cocaine and other drugs of its class may have a greater potential for enhancing the addiction process among adolescents than among adults, both of which are growing populations exposed to MP (Shaffer 1994; Robin 1999). Given that the use of therapeutic stimulants has become extended (Heiligenstein et al. 1999) and that adolescents may be more sensitive to aspects of the drug that make it more reinforcing, our animal model was appropriate for studies on the effects of adolescent MP exposure.

\section{Cross Sensitization from MP to Cocaine}

A dose of $10 \mathrm{mg} / \mathrm{kg}$ MP produces more locomotor activity than higher or lower doses of the drug (Gaytan et al. 1997; Crawford et al. 1998; McDougall et al. 1999), an effect observed in both young and older animals. We found that 2 weeks following repeated treatment with MP (10 mg/kg IP), a threshold challenge dose of cocaine $(7.5 \mathrm{mg} / \mathrm{kg}$ IP) significantly enhanced ambulations and rearing, as compared to saline-treated animals. Thus, pretreatment with moderate doses of MP is capable of supporting persistent cross sensitization to cocaine. Similar results were also obtained when we halved the dose of MP to $5 \mathrm{mg} / \mathrm{kg}$ and increased the challenge cocaine dose to $15 \mathrm{mg} / \mathrm{kg}$.

Enhanced locomotor responses are not characteristic in humans taking MP therapeutically. Indeed, reduction of hyperactivity is the desired response. Therefore, the animal results showing increased locomotor responses following repeated treatment with psychostimulants may have less relevance to human behavior. Humans taking MP therapeutically, although exposed intermittently over long periods of time, do not develop hyperactivity except in the form of motor tics (Borcherding et al. 1990; Castellanos et al. 1997; Nolan and Gadow 1997), mostly occurring at higher doses.

Accordingly, we next tested a lower dose of MP (2 $\mathrm{mg} / \mathrm{kg}$ ), one that is well within the range for attaining 
therapeutic peak plasma levels, although actually lower than therapeutically sustained levels and one that will activate the DA system in rodents (Gerasimov et al. 2000). After repeated treatment with this dose of MP, we no longer observed cross sensitization to the locomotor stimulant effects of cocaine. Given that context-independent sensitization is dose-dependent (Browman et al. 1998) and the importance of context for obtaining sensitization is well established (Robinson et al. 1998; Fraioli et al. 1999), it is possible that cross sensitization to cocaine might have been detected had we measured activity in the home cage. Indeed, MP at doses as low as $1.0 \mathrm{mg} / \mathrm{kg}$ IP produces context-dependent sensitization to a $2.5 \mathrm{mg} / \mathrm{kg}$ challenge dose of MP following repeated exposure (Kuczenski and Segal 2001) in adult rats.

\section{Adolescent Exposure to MP Enhances Cocaine Self-Administration in Adult Rats}

Animal studies clearly show that pre-exposure to psychomotor stimulants enhances subsequent SA of such drugs (Horger et al. 1990, 1991, 1992; Pierre and Vezina 1997; Vezina et al. 1999; Lorrain et al. 2000). Consistent with pre-exposure to nicotine (Horger et al. 1992), and low-dose exposure to amphetamine (Pierre and Vezina 1997) we found a differential effect of low-dose MP preexposure on the reinforcing and locomotor activating effects of cocaine. Low-dose pre-exposure to MP enhanced the reinforcing effects of cocaine but not its locomotor stimulant effects.

The impact of the psychostimulants on reward processes is of particular interest, because some authors have attributed behavioral aberrations in ADHD to an elevated reward threshold (see Solanto 1998 for review). Wilkison and colleagues (1995) reported that in children with ADHD, MP increased the total number of button-presses to obtain monetary reinforcement on a progressive ratio schedule. This suggests that MP increased efficacy of reinforcement or reduced reward threshold in these subjects. We must assume that treatment did not increase their activity, because this drug is known to reduce the hyperactive behavior associated with ADHD. Therefore, the reinforcement-enhancing qualities of MP acted in a therapeutic capacity in a paradigm similar to those used to characterize the reinforcement-enhancing qualities of drugs of abuse. Our findings can be considered consistent with other results showing that MP increases reinforcement efficacy of low reinforcers (Heyman 1992), in our case, a low dose of cocaine. In the case of ADHD, MP may enhance school performance by augmenting the relative value of socially mediated reinforcers over monetary reward.

Conditions that induce sensitization to the behavioral effects of cocaine also increase extracellular levels of DA in the nucleus accumbens (Pettit and Justice 1989; Kalivas and Duffy 1990; see White and Kalivas 1998 for review). One of the long-lasting alterations following repeated psychostimulant administration that may contribute to increased extracellular DA levels is reduction in DAT synthesis in the prefrontal cortex and NAc (see Kuhar and Pilotte 1996 for review). Consistent with these findings, therapeutic treatment with MP decreases DAT binding in ADHD patients who had previously presented with increased DAT binding compared to age- and sex-matched controls (Krause et al. 2000). Treatment with MP lowers increased striatal DAT availability, suggesting a potential mechanism for MP's therapeutic effect. This implies that one of the alterations shown to occur following repeated cocaine might also occur following repeated low-dose exposure to MP; thereby, creating neuroadaptations associated with both therapeutic effects and drug vulnerability, complicating interpretations of clinical studies and perhaps accounting in part for inconsistencies in clinical studies on the relationship between ADHD and drug dependence.

We suggest that our findings support the hypothesis that the beneficial behavioral effect of MP is derived from alterations in brain substrates mediating the increased incentive value of low reinforcers. However, to the extent that our protocols produce therapeutically relevant plasma and brain levels of MP with appropriate temporal patterning (which we have tried to maximize based on previous controlled studies in rats) our results also suggest that adolescent exposure to MP may potentially increase future vulnerability to low doses of cocaine. This is the first evidence from carefully controlled laboratory experiments that adolescent exposure to MP can facilitate psychostimulant selfadministration in adult rodents. As such, this report sends a cautionary warning to the continued escalation of MP use in children. Of course, continued careful clinical studies will be needed to verify the extent to which our findings accurately reflect the clinical situation.

\section{ACKNOWLEDGMENTS}

This work was supported by National Institute on Drug Abuse Grant DA04093 (FJW), Senior Scientist Award DA00456 (FJW), and National Research Service Award DA05931 (CLB). In addition, the self-administration study was supported in part by an equipment grant to CLB from MED Associates of St. Albans, Vermont. We thank Dr. Nadine Lambert for providing prepublication information regarding her recent studies.

\section{REFERENCES}

Biederman J, Wilens T, Mick E, Spencer T (1999): Pharmacotherapy of ADHD reduces the risk for substance use disorder. Pediatrics 104(2):e20 
Biederman J, Wilens T, Mick E, Milberger S, Faraone S, Spencer T (1995): Psychoactive substance abuse disorder in adults with attention deficit hyperactivity disorder. Am J Psychiat 152:1652-1658

Borcherding BG, Deysor CS, Rapoport JL, Elia J, Amass J (1990): Motor/vocal tics and compulsive behaviors on stimulant drugs: Is there a common vulnerability? Psychiat Res 33:83-94

Browman KE, Badiani A, Robinson TE (1998): The influence of environment on the induction of sensitization to the psychomotor activating effects of intravenous cocaine in rats is dose-dependent. Psychopharmacology 137:90-98

Castellanos FX, Giedd JN, Elia J, Marsh WL, Ritchie GF, Hamburger SD, Rapoport JL (1997): Controlled stimulant treatment of ADHD and comorbid Tourette's syndrome: Effects of stimulant and dose. J Am Acad Child Adolesc Psychiat 36:589-596

Clure C, Brady KT, Saladin ME, Johnson D, Waid R, Rittenbury M (1999): Attention deficit/hyperactivity disorder and substance use: Symptoms patterns and drug choice. Am J Drug Alcohol Abuse 25:441-448

Crawford CA, McDougall SA, Meier TL, Collins RL, Watson JB (1998): Repeated methylphenidate treatment induces behavioral sensitization and decreases protein kinase $\mathrm{A}$ and dopamine-stimulated adenylyl cyclase activity in the dorsal striatum. Psychopharmacology 136:34-43

Estroff TW, Schwartz RH, Hoffman NG (1989): Adolescent cocaine abuse: Addictive potential, behavioral, and psychiatric effects. Clin Pediat 28:550-555

Fraioli S, Crombag HS, Badiani A, Robinson TE (1999): Susceptibility to amphetamine-induced locomotor sensitization is modulated by environmental stimuli. Neuropsychopharmacology 20:533-541

Garland EJ (1998): Pharmacotherapy of adolescent attention deficit hyperactivity disorder: Challenges, choices, caveats. J Psychopharmacol 12:385-395

Gaytan O, al-Rahim S, Swann A, Dafny N (1997): Sensitization to locomotor effects of methylphenidate in the rat. Life Sci 61:PL101-107

Gerasimov MR, Franceschi M, Volkow ND, Gifford A, Gatley SJ, Marsteller D, Molina PE, Dewey SL (2000): Comparison between intraperitoneal and oral methylphenidate administration: A microdialysis and locomotor activity study. J Pharmacol Exp Ther 295:51-57

Heiligenstein E, Guenther G, Levy A, Savino F, Fulwiler J (1999): Psychological and academic functioning in college students with ADHD. J Am Coll Health 47:181-185

Henry DJ, White FJ (1995): The persistence of behavioral sensitization to cocaine parallels enhanced inhibition of nucleus accumbens neurons. J Neurosci 15:6287-6299

Heyman GM (1992): Effects of methylphenidate on response rate and measures of motor performance and reinforcement efficacy. Psychopharmacology 109:145-152

Horger BA, Giles MK, Schenk S (1992): Pre-exposure to amphetamine and nicotine predisposes rats to selfadminister a low dose of cocaine. Psychopharmacology 107:271-276

Horger BA, Shelton K, Schenk S (1990): Pre-exposure sensitizes rats to the rewarding effects of cocaine. Pharmacol Biochem Behav 37:707-711

Horger BA, Wellman PJ, Morien A, Davies BT, Schenk S
(1991): Caffeine exposure sensitizes rats to the reinforcing effects of cocaine. NeuroReport 2:53-56

Izenwasser S, Coy AE, Ladenheim B, Loeloff RJ, Cadet JL, French D (1999): Chronic methylphenidate alters locomotor activity and dopamine transporters differently from cocaine. Eur J Pharmacol 373:187-193

Kalivas PW, Duffy P (1990): Effect of acute and daily cocaine treatment on extracellular dopamine in the nucleus accumbens. Synapse 5:48-58

Koob GF, Bloom FE (1988): Cellular and molecular mechanisms of drug dependence. Science 242:715-723

Krause KH, Dresel SH, Krause J, Kung HF, Tatsch K (2000): Increased striatal dopamine transporter in adult patients with attention deficit hyperactivity disorder: Effects of methylphenidate as measured by single photon emission computed tomography. Neurosci Lett 285:107-110

Kuczenski R (1983): Biochemical actions of amphetamine and other stimulants. In Creese I (ed), Stimulants: Neurochemical, Behavioral, and Clinical Perspective. New York, Raven Press, pp 31-61

Kuczenski R, Segal DS (1997): Effects of methylphenidate on extracellular dopamine, serotonin, and norepinephrine: Comparison with amphetamine. J Neurochem 68: 2032-2037

Kuczenski R, Segal DS (2001): Locomotor effects of acute and repeated threshold doses of amphetamine and methylphenidate: Relative roles of dopamine and norepinephrine. J Pharmacol Exp Ther 296:876-883

Kuhar MJ, Pilotte NS (1996): Neurochemical changes in cocaine withdrawal. Trends Pharmacol Sci 17:260-264

Lambert NM (in press): Stimulant treatment as a risk factor for nicotine use and substance abuse. In PS Jensen and JR Cooper (eds), Diagnosis and Treatment of ADHD: An evidence-based approach. Chicago, American Medical Association Press

Lambert NM, Hartsough CS (1998): Prospective study of tobacco smoking and substance dependence among samples of ADHD and non-ADHD subjects. J Learn Disabil 31:533-544

Laviola G, Wood RD, Kuhn C, Francis R, Spear LP (1995): Cocaine sensitization in periadolescent and adult rats. $J$ Pharmacol Exp Ther 275:345-357

Laviola G, Adriana W, Terranova ML, Gerra G (1999): Psychobiological risk factors for vulnerability to psychostimulants in human adolescents and animal models. Neurosci Biobehav Rev 23(7):993-1010

Lorrain DS, Arnold GM, Vezina P (2000): Previous exposure to amphetamine increases incentive to obtain the drug: Long-lasting effects revealed by the progressive ratio schedule. Behav Brain Res 107:9-19

Marshall E (2000): Duke study faults overuse of stimulants for children. Science 289:721

McDougall SA, Collins RL, Karper PE, Watson JB, Crawford CA (1999): Effects of repeated methylphenidate treatment in the young rat: Sensitization of both locomotor activity and stereotyped sniffing. Exp Clin Psychopharmacol 7:208-218

McDougall SA, Duke MA, Bolanos CA, Crawford CA (1994): Ontogeny of behavioral sensitization in the rat: Effects of direct and indirect dopamine agonists. Psychopharmacology 116:483-490 
McNamara CG, Davidson ES, Schenk S (1993): A comparison of the motor-activating effects of acute and chronic exposure to amphetamine and methylphenidate. Pharmacol Biochem Behav 45:729-732

National Institute of Mental Health (1999): Long-term effects of stimulant medications on the brain: Possible relevance to the treatment of ADHD. Report on Workshop Dec 1-2, 1999 http: / / www.nimh.nih.gov/events/adhdwork shop.cfm

Nolan EE, Gadow KD (1997): Children with ADHD and tic disorder and their classmates. Behavioral normalization with methylphenidate. J Am Acad Child Adoles Psychiat 36:597-604

Parran TV, Jasinski DR (1991): Intravenous methylphenidate abuse. Prototype for prescription drug abuse. Arch Intern Med 151:781-783

Pettit HO, Justice JB (1989): Dopamine in the nucleus accumbens during cocaine self-administration as studied by in vivo microdialysis. Pharmacol Biochem Behav 34:899-904

Piazza PV, Le Moal M (1996): Pathophysiological basis of vulnerability to drug abuse: Role of an interaction between stress, glucocorticoids, and dopaminergic neurons. Ann Rev Pharamacol Toxicol 36:359-378

Pierre PJ, Vezina P (1997): Predisposition to self-administer amphetamine: The contribution of response to novelty and prior exposure to the drug. Psychopharmacology 129:277-284

Ritz MC, Lamb RJ, Goldberg SR, Kuhar MJ (1987): Cocaine receptors on dopamine transporters are related to selfadministration of cocaine. Science 237:53-62

Robin AL (1999): Attention deficit/hyperactivity disorder in adolescents. Common pediatric concerns. Pediat Clin North Am 46:1027-1038

Robinson TE, Becker JB (1986): Enduring changes in brain and behavior produced by chronic amphetamine administration: A review and evaluation of animal models of amphetamine psychosis. Brain Res Rev 11: 157-198

Robinson TE, Berridge KC (1993): The neural basis of drug craving: An incentive-sensitization theory of addiction. Brain Res Rev 18:247-291

Robinson TE, Browman KE, Crombag HS, Badiani A (1998): Modulation of the induction or expression of psychostimulant sensitization by the circumstances surrounding drug administration. Neurosci Biobehav Rev 22: 347-354

Scahill L, Schwab-Stone M (2000): Epidemiology of attention deficit hyperactivity disorder in school-age children. Child Adolesc Psychiat Clin N Am 9:541-555

Schenk S, Davidson ES (1998): Stimulant pre-exposure sensitizes rats and humans to the rewarding effects of cocaine. NIDA Res Monograph No.169. pp 56-82

Schubiner H, Tzelepsis A, Milberger S, Lockhart N, Kruger M, Kelley BJ, Schoeurer EP (2000): Prevalence of attention deficit/hyperactivity disorder and conduct disorder among substance abusers. J Clin Psychiat 61:244-251

Self DW, Nestler EJ (1995): Molecular mechanisms of drug reinforcement and addiction. Ann Rev Neurosci 18: 463-495

Shaffer D (1994): Attention deficit hyperactivity disorder in adults. Am J Psychiat151:633-638
Shuster L, Hudson J, Anton M, Righi D (1982): Sensitization of mice to methylphenidate. Psychopharmacology 77: $31-36$

Silver LB (2000): Attention deficit/hyperactivity disorder in adult life. Child Adoles Psychiat Clin N Am 9:511-523

Snyder KJ, Katovic NM, Spear LP (1998): Longevity of the expression of behavioral sensitization to cocaine in preweanling rats. Pharmacol Biochem Behav 60:909-914

Solanto MV (1998): Neuropsychopharmacological mechanisms of stimulant drug action in attention deficit hyperactivity disorder: A review and integration. Behav Brain Res 94:127-152

Spencer T, Biederman J, Wilens T (2000): Pharmacotherapy of attention deficit hyperactivity disorder. Child Adoles Psychiat Clin N Am 9:77-97

Swanson JM, Seargeant JA, Taylor E, Sonuga-Barke EJS, Jensen PS, Cantwell DP (1998): Attention deficit disorder and hyperkinetic disorder. Lancet 351:429-433

Tirelli E, Ferrara M (1997): Neonatal and pre-weanling rats are able to express short-term behavioral sensitization to cocaine. Eur J Pharmacol 328:103-114

Ujike H, Tsuchida K, Akiyama K, Fujiwara Y, Kuroda S (1995): Ontogeny of behavioral sensitization to cocaine. Pharmacol Biochem Behav 50:613-617

Valdez A, Schenk S (1994): Persistence of the ability of amphetamine pre-exposure to facilitate acquisition of cocaine self-administration. Pharmacol Biochem Behav 47:203-205

Vezina P, Pierre PJ, Lorrain DS (1999): The effect of previous exposure to amphetamine on drug-induced locomotion and self-administration of a low dose of the drug. Psychopharmacology 14:125-134

Volkow ND, Wang GJ, Fowler JS, Fischman M, Foltin R, Abumrad NN, Gatley SJ, Logan J, Wong C, Gifford A, Ding YS, Hitzemann R, Pappas N (1999): Methylphenidate and cocaine have a similar in vivo potency to block dopamine transporters in the human brain. Life Sci 65:PL7-12

Volkow ND, Wang G-J, Fowler JS, Logan J, Gerasimov M, Maynard L, Ding Y-S, Gatley SJ, Gifford A, Franceschi D (2001):Therapeutic doses of oral methylphenidate significantly increase extracellular dopamine in the human brain. J Neurosci 21(RC121):1-5

Volkow ND, Wang G-J, Fowler JS, Gatley JS, Logan J, Ding Y-S, Hitzemann R, Pappas N (1998): Therapeutic doses of oral methylphenidate induce significant levels of dopamine transporter occupancies in the human brain. Am J Psychiat 155:1325-1331

White FJ, Kalivas PW (1998): Neuroadaptations involved in amphetamine and cocaine addiction. Drug Alcohol Depend 51:141-153

White FJ, Wolf ME (1991): Psychomotor stimulants. In Pratt JA (ed), The Biological Basis of Drug Tolerance and Dependence. London, Academic Press, pp 153-197

Wilens TE, Biederman J, Mick E, Faraone SV, Spencer T (1997): Attention deficit hyperactivity disorder is associated with early onset substance use disorders. J Nerv Mental Dis 185:475-482

Wilkison PC, Kircher JC, McMahon WM, Sloane HN (1995): Effects of methylphenidate on reward strength in boys 
with attention deficit hyperactivity disorder. J Am Acad Child Adoles Psychiat 34:897-901

Wood RD, Tirelli E, Snyder KJ, Heyser CJ, LaRocca TM, Spear LP (1998): Evidence for behavioral sensitization to cocaine in pre-weanling rat pups. Psychopharmacology 138:114-123
Zavala AR, Nazarian A, Crawford CA, McDougall SA (2000): Cocaine-induced behavioral sensitization in the young rat. Psychopharmacology 151:291-298

Zito JM, Safer DJ, dosReis S, Gardner JF, Boles M, Lynch F (2000): Trends in the prescribing of psychotropic medication to preschoolers. JAMA 283:1025-1030 